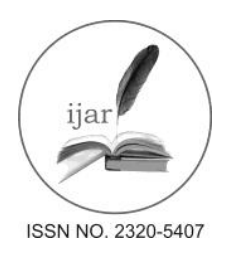

Journal homepage:http://www.journalijar.com

Journal DOI:10.21474/IJAR01

\section{RESEARCH ARTICLE}

\title{
OPTIMIZATION OF COATING TIME OF HYDROCOLLOID BASED EDIBLE COATING FOR SHELF LIFE EXTENSION OF LIGHT RED TOMATOES.
}

INTERNATIONAL JOURNAL

OF ADVANCED RESEARCH

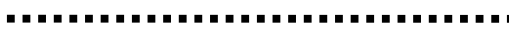

Sudhanshu Billoria*and Hari Niwas Mishra.

Agricultural \& Food Engineering Department, Indian Institute of Technology Kharagpur, Kharagpur, West Bengal 721302, India.

\section{Manuscript Info}

Manuscript History:

Received: 15 May 2016

Final Accepted: 19 June 2016

Published Online: July 2016

Key words:

Coating time, coating pickup, edible coating, tomatoes.

*Corresponding Author

Sudhanshu Billoria.

\begin{abstract}
The aim of the study was to optimize the coating time of the hydrocolloid based edible coating for the light red stage tomatoes. The coating was applied onto the tomatoes by the dipping method for the different coating times varying from 0.5 to $5 \mathrm{~min}$ (i.e. $30 \mathrm{~s}, 1 \mathrm{~min}, 2 \mathrm{~min}, 3 \mathrm{~min}, 4 \mathrm{~min}$ and 5 min) and various responses like gas concentration, physiological weight loss $\left(\mathrm{PL}_{\mathrm{w}}\right)$ of tomatoes, coating thickness and coating pick up were studied. The tomatoes coated for 4 min were found to have the least $\mathrm{PL}_{\mathrm{w}}(3.43 \%)$ and minimum change in gas concentration with $1.1 \%$ carbon dioxide $\left(\mathrm{CO}_{2}\right)$ and $19.4 \%$ oxygen $\left(\mathrm{O}_{2}\right)$, whereas control sample registered higher values of moisture loss $(9.42 \pm 1.84 \%)$ and $3.5 \% \mathrm{CO}_{2}$ and $14.9 \% \mathrm{O}_{2}$ after 5 days of storage at $10{ }^{\circ} \mathrm{C}$ and $85 \%$ relative humidity. The coating pickup for the tomatoes coated for 4 min was of $4.9 \pm 0.3$ and coating thickness $12.5 \pm 0.87$ micron. The treatment was found to have a significant reduction in moisture loss and respiration rate at 5\% significant level effect on the responses studied.
\end{abstract}

Copy Right, IJAR, 2016,. All rights reserved.

\section{Introduction:-}

Tomato is globally the second most important vegetable crop after the potato. With an annual production of 18.2 MT during the year 2013, India ranks $2^{\text {nd }}$ after China, contributing around $11 \%$ in the total world production (163 MT) of tomato (FAOSTAT, 2013). Tomato is a major contributor of carotenoids (especially lycopene), phenolics, vitamin C and small amounts of vitamin E in daily diets (Pila et al., 2010). In order to prolong their availability in the market throughout the year, the perishable commodities like tomato (Mojevic and Tesanovic, 2011; Tosati et al., 2015) need to be handled and stored with due care. Certain postharvest constraints, including short shelf life due to respiration, moisture loss, ripening and susceptibility to diseases limit their long duration storage and transportation. Tomatoes being a climacteric fruit, the start of ripening is accomplished by a rapid rise in respiration rate called "respiratory climacteric" during which oxidative breakdown of complex substrates occurs, followed by ageing, leading to product deterioration (Babu et al., 2014; Srividya et al., 2014). Also tomatoes being fleshy fruits, continue to lose water after harvest. This results in a wilted, dull appearance that reduces the eye appeal and freshness and eventually becomes unmarketable.

The edible coatings is a tool that provides control of moisture loss, retardation of senescence and browning in cut produce, reduction in respiration rate and can ultimately prolong the shelf life. Therefore, the edible coating is a technology that can address all the issues associated with the spoilage of tomatoes, and can potentially extend their shelf life. Edible coating is defined as an edible material (protein, polysaccharide or lipid) that is used as a thin layer on the surface of foods (Gonzalez-Aguilar et al., 2010). It can be applied for, providing a selective barrier to oxygen, carbon dioxide and moisture, preserving fresh-cut vegetables and fruits, improving textural and mechanical properties, preventing flavor loss and carrying food additives (Tapia et al., 2008).

The edible coatings act as immediate packaging as they form a layer directly over the surface of the food material forming a film over it and limiting the gas exchanges at the cellular and surface level. As it is a sort of immediate 
packaging, and there is very little space between the food surface and the film, the equilibrium conditions can be attained quickly. But for an effective edible coating, there are various factors that need to be considered such as coating time, coating concentration, conditions of coatings (like temperature). The coating time is a crucial parameter, as it decides the thickness of coating, which can greatly affect the major parameters affecting shelf life of fresh produce such as respiration rate, moisture loss, firmness etc. The other parameters (coating concentration and temperature) have been studied and are a part of a separate study. The present study includes the optimization of coating time for a hydrocolloid based edible coating (by dipping method) for the shelf life extension of light red stage tomatoes. The effect of coating time on the physiological weight loss of tomatoes, change in package concentration, coating pickup and thickness of the edible coating was studied.

\section{Materials and methods:-}

Fresh tomatoes were purchased from thelocal market of Indian Institute of Technology Kharagpur, India. The fruits with uniform size, shape, color and external appearance and also free from fungal infection were taken for the experiment. Samples were washed using chlorinated water $(200 \mathrm{ppm})$ for $2 \mathrm{~min}$ and then left to dry at room temperature for about 1 hour. Tomatoes were chosen randomly for the application of coating on it, for each experiment 5 tomatoes were taken, 10 for the study of coated sample and 10 for control study.

\section{Preparations of Edible Coating:-}

Food-grade hydrocolloid based materials were purchased from sigma Aldrich and preparation of coating has been done according to the Tapia et al., (2008) with minor modifications. Briefly, the coating solution was prepared by mixing the components of the coating in the Millipore water and with continuous stirring on a magnetic stirrer. The coating solution was then heated at a controlled temperature of $70{ }^{\circ} \mathrm{C}$ in a water bath for $30 \mathrm{~min}$, until the mixture became clear. Then, the prepared coating was homogenized within IKA Ultra Turrax T18 basic (IKAs WERKE, Germany) with a S18N-10G probe, for $5 \mathrm{~min}$ at $24000 \mathrm{rpm}$ to form emulsions, and degassed under vacuum at 80 mbar. Once prepared, film-forming solutions/emulsions were used for coating the tomatoes.

The tomatoes were randomly chosen for the different treatments, and dipped into the prepared coating solution for different times ranging from $30 \mathrm{~s}$ to $5 \mathrm{~min}$ i.e. $30 \mathrm{~s}, 1 \mathrm{~min}, 2 \mathrm{~min}, 3 \mathrm{~min}, 4 \mathrm{~min}$ and $5 \mathrm{~min}$ at room temperature and then excess coating materials were allowed to drip off. After dipping in the coating solutions, the tomatoes were dried at ambient conditions and a fan generating low speed air was used to hasten the drying. Ten tomatoes were used for each treatment and for each study (physiological weight loss, coating pickup, respiration rate and coating thickness) and control samples (10 in no.) without any coating were also kept for comparison with the coated tomatoes.

\section{Physiological weight loss:-}

For determining the physiological loss $\left(\mathrm{PL}_{\mathrm{w}}\right)$ in weight, fruits were weighed before imposing the treatment which served as the initial fruit weight. The coating was applied to tomatoes for different duration of times ranging from 30 $\mathrm{s}$ to $5 \mathrm{~min}$ i.e. $30 \mathrm{~s}, 1 \mathrm{~min}, 2 \mathrm{~min}, 3 \mathrm{~min}, 4 \mathrm{~min}$ and $5 \mathrm{~min}$. The coated tomatoes were kept in open at normal ambient conditions and loss in weight of the tomatoes was recorded on each day for the 5 days and the difference was calculated as the percent weight loss as given by the following equation:

$$
P L_{w}=\frac{W_{i}-W_{f}}{W_{i}} \times 100
$$

Where, $\mathrm{W}_{\mathrm{i}}$ is the initial weight of tomatoes before coating, $\mathrm{W}_{\mathrm{f}}$ is the final weight of tomatoes and $\mathrm{PL}_{\mathrm{w}}$ is the physiological weight loss or moisture loss of tomatoes.

\section{Coating pickup:-}

Coating pick-up was determined by the difference in weight of tomatoes before and after the coating process. The coated fruit was consistently dried under forced-air of a table fan for 5 minutes before weight measurement. The procedure for measurement of coating pick-up has been described by previous study(Hsia et al., 1992; Maskat et al., 2005; Zahid et al., 2011) with minor modifications. Briefly, the weighed amount of coating solution was taken in a beaker which was tared before putting the coating solution and the tomatoes (around $0.5 \mathrm{~kg}$ ) which were weighed individually before adding into the coating. The tomatoes were dipped into the coating solution for $30 \mathrm{~s}, 1 \mathrm{~min}, 2$ min, $3 \mathrm{~min}, 4 \mathrm{~min}$ and $5 \mathrm{~min}$. The tomatoes coated for the different times were taken out and the excess coating was allowed to drip for $2 \mathrm{~min}$ into the coating solution. The weight of the coating solution was measured at the end of 
each dipping + dripping time (time for which coating was allowed to drip into the coating solution). The coating pickup was calculated by the difference in the weight of coating solution (initial weight minus final weight).

\section{Gas concentration in the package:-}

The coated tomatoes with the different coating times were put into the glass containers and sealed airtight by using the closed system respirometer method (respiration rate measurement method) as described by Bhande and Goswami, 2008. The containers were stored at $10{ }^{\circ} \mathrm{C}$ and $85 \%$ relative humidity in thermostatically controlled environmental test chambers. Gas composition of respirometer was analyzed at regular period of one day interval till 5 days. Headspace gas sample was taken with the help of sampling needle, which was inserted through a silicon disc into the respirometer and analyzed quantitatively for $\mathrm{O}_{2}$ and $\mathrm{CO}_{2}$ concentrations using a headspace $\mathrm{O}_{2} / \mathrm{CO}_{2}$ gas analyzer (Systech Illinois, 6600). In the headspace analyzer, a zirconium sensor is used for $\mathrm{O}_{2}$ determination and an infrared detector is used to detect $\mathrm{CO}_{2}$. All measurements were taken in triplicate.

\section{Thickness:-}

The uncoated fresh tomatoes were taken and a very thin section of tomato skin was peeled off. All the possible pulp was scraped out from the skin and attempt was made to make the thickness of the tomato skin uniform. The thickness of the tomato skin was measured at random positions. The section of tomato skin was dipped into the coating solution for different time duration and allowed to dry. After the coating is dried, the thickness of skin was measured again and the difference in thickness was divided by two, as in this case, the peel is getting coated from two sides unlike the whole tomatoes that will be coated only on the surface.

\section{Results and Discussion:-}

Physiological weight $\operatorname{loss}\left(\mathbf{P L}_{\mathrm{w}}\right)$ :-

Weight loss in fruits and vegetables can be attributed to water loss because other components like gaseous products of respiration, aroma or flavor are practically undetectable in terms of weight (Olivas and Barbosa-Canovas, 2005).The cumulated physiological weight loss of coated tomatoes was studied up to days of storage at room temperature and it varied significantly $(\mathrm{p}<0.1)$ with change in duration of the coating time. The control tomatoes, that is, the uncoated tomatoes showed the highest weight loss over the duration of five days ranging from $2.64 \pm$ $0.45 \%$ to $9.42 \pm 1.84$ on day 1 and day 5 , respectively. The weight loss data of uncoated tomatoes was similar to that of reported in the literature (Bhattarai and Gautam), 2006; Moneruzzaman et al., 2009).Also the $\mathrm{PL}_{\mathrm{w}}$ decreased with the increase in coating time, which can be attributed to the fact that the edible coatings have the potential to reduce moisture loss (Azaraksh et al., 2012). However, the weight loss was found to increase at 5 min of coating duration (Fig. 1), and this trend was found on each day of storage. The hydrophilic nature of coating material could be responsible for this effect. The similar trend was reported byAzaraksh et al. (2012). The tomatoes coated for $4 \mathrm{~min}$ showed a minimum weight loss as compared to the other durations as shown in Table 1. 


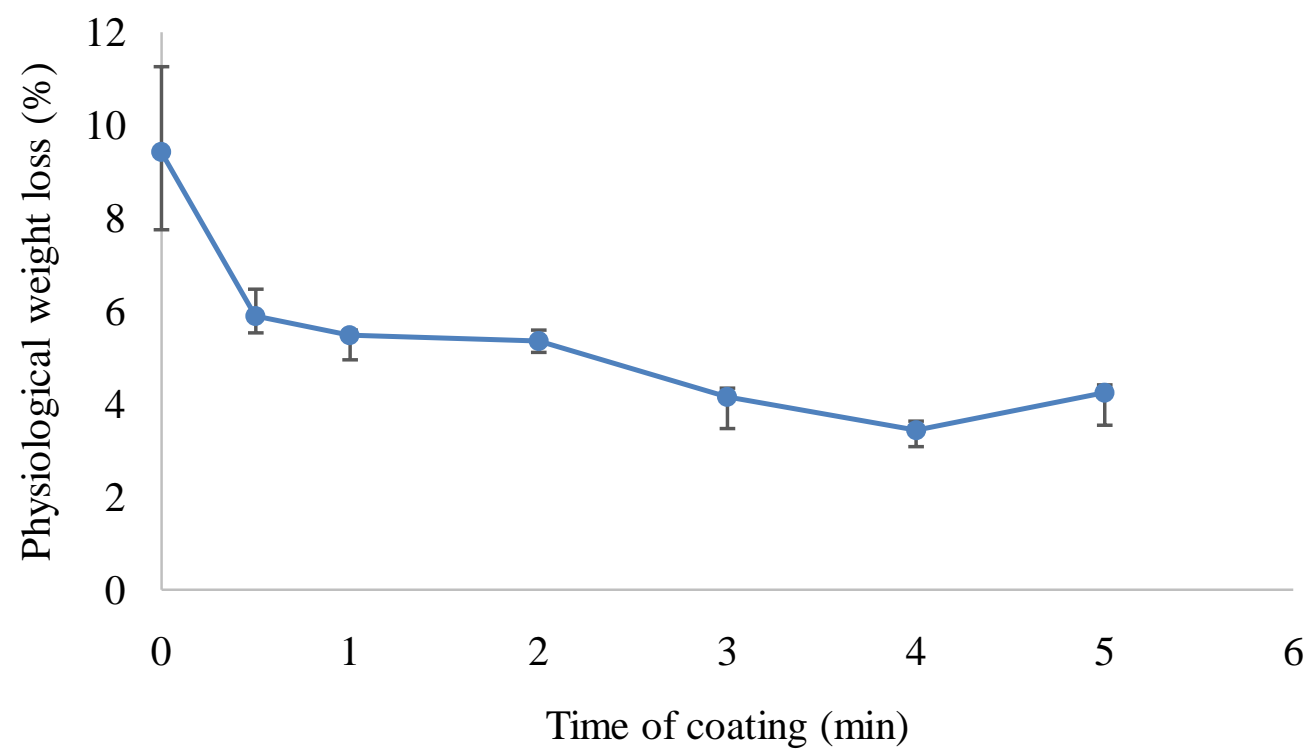

Figure 1:- Physiological weight loss of tomatoes coated with edible coating for different coating time after 5 days of storage at room temperature.

Table 1:- Physiological weight loss during storageof tomatoes coated with edible coating for different coating time

\begin{tabular}{|c|c|c|c|c|c|}
\hline \multirow{2}{*}{$\begin{array}{c}\text { Time of coating } \\
(\mathrm{min})\end{array}$} & \multicolumn{5}{|c|}{ Weight loss of tomatoes (\%) during storage at room temperature till five days } \\
\cline { 2 - 6 } & 1 & 2 & 3 & 4 & 5 \\
\hline 0 & $2.64 \pm 0.45$ & $4.02 \pm 1.23$ & $5.7 \pm 0.36$ & $8.6 \pm 1.67$ & $9.42 \pm 1.84$ \\
\hline 30 & $0.225 \pm 0.005$ & $1.73 \pm 0.85$ & $3.23 \pm 0.46$ & $4.66 \pm 0.36$ & $5.89 \pm 0.58$ \\
\hline 1 & $0.218 \pm 0.071$ & $1.59 \pm 0.32$ & $2.96 \pm 0.15$ & $4.36 \pm 0.52$ & $5.47 \pm 0.12$ \\
\hline 2 & $0.215 \pm 0.008$ & $1.56 \pm 0.49$ & $2.91 \pm 0.27$ & $4.27 \pm 0.24$ & $5.35 \pm 0.24$ \\
\hline 3 & $0.212 \pm 0.025$ & $1.45 \pm 0.36$ & $2.76 \pm 0.31$ & $3.92 \pm 0.68$ & $4.15 \pm 0.19$ \\
\hline 4 & $0.167 \pm 0.032$ & $1.15 \pm 0.21$ & $2.16 \pm 0.11$ & $3.21 \pm 0.54$ & $3.43 \pm 0.11$ \\
\hline 5 & $0.204 \pm 0.033$ & $1.51 \pm 0.38$ & $2.84 \pm 0.21$ & $3.89 \pm 0.69$ & $4.24 \pm 0.17$ \\
\hline
\end{tabular}

\section{Coating pickup:-}

The coating time significantly affected $(p<0.05)$ the amount of coating used for coating of tomatoes. All the sample means from different coating durations were found significantly different, except for the 0.5 and $1 \mathrm{~min}$ coating duration which did not show any significant difference as represented by the mean comparison plot of Tukey's test in Fig. 2.The amount of coating pickup varied from $0.21 \pm 0.015 \%$ to $0.56 \pm 0.03 \%$ for 0.5 min and 5 min, respectively. The amount of coating pickup was calculated for $1 \mathrm{~kg}$ of tomatoes, $5.6 \mathrm{~g}$ of edible coating sufficient to coat $1 \mathrm{~kg}$ of tomatoes. The results for amount coating pickup for different durations of coating time are presented in Table 2.

Table 2:-Coating pickup of edible coating for different durations of coating time.

\begin{tabular}{|c|c|c|c|c|}
\hline $\begin{array}{c}\text { Time of coating } \\
(\mathrm{min})\end{array}$ & Coating pickup (g) & Weight of tomatoes & Coating pickup (\%) & $\begin{array}{c}\text { Coating pickup in g } \\
\text { per kg of tomatoes }\end{array}$ \\
\hline 0.5 & $1.02 \pm 0.015$ & $485.71 \pm 4.04$ & $0.21 \pm 0.015$ & $2.1 \pm 0.1$ \\
\hline 1 & $1.085 \pm 0.014$ & $474.26 \pm 4.35$ & $0.228 \pm 0.019$ & $2.28 \pm 0.3$ \\
\hline 2 & $1.778 \pm 0.055$ & $490.03 \pm 3.87$ & $0.362 \pm 0.012$ & $3.62 \pm 0.08$ \\
\hline 3 & $1.913 \pm 0.061$ & $497.26 \pm 4.89$ & $0.384 \pm 0.023$ & $3.84 \pm 0.5$ \\
\hline 4 & $2.429 \pm 0.15$ & $495.52 \pm 5.41$ & $0.49 \pm 0.09$ & $4.9 \pm 0.3$ \\
\hline 5 & $2.85 \pm 0.09$ & $508.33 \pm 6.03$ & $0.56 \pm 0.03$ & $5.6 \pm 0.7$ \\
\hline
\end{tabular}




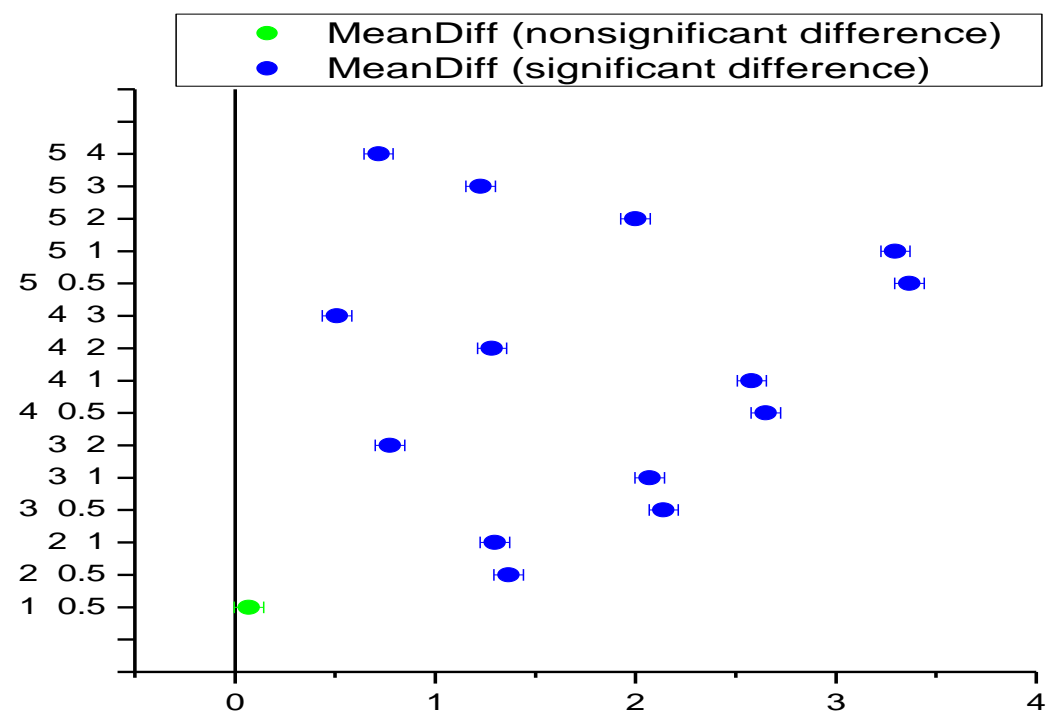

Figure 2:-Mean comparison plot of Tukey's test for different times of coating duration.

\section{Gas concentration:-}

The edible coatings are said to have potential for the reduction of respiration rate of fresh fruits and vegetables (Olivas and Barbosa-Canovas, 2005). This effect can be associated with the reduction in metabolic activities such as respiration rate and decrease in concentration of oxygen $\left(\mathrm{O}_{2}\right)$ and increase in carbon dioxide $\left(\mathrm{CO}_{2}\right)$ concentration (Olivas and Barbosa-Canovas, 2005; Gonzalez-Aguilar et al., 2010). The edible coatings as immediate packaging that is formed directly over the surface of the food product. Therefore, by forming a film over the surface, it limits the gas exchanges at the cellular and surface level. It has the selective permeation for oxygen and carbon dioxide, which may slow down the interchange of $\mathrm{CO}_{2}$ and $\mathrm{O}_{2}$ between the environment and the coated fruit (GonzalezAguilar et al., 2010). This effect was evident in the present study also, where the uncoated tomato fruits showed the maximum change in concentration of $\mathrm{O}_{2}$ and $\mathrm{CO}_{2}$ with the $3.5 \% \mathrm{CO}_{2}$ and $14.9 \% \mathrm{O}_{2}$ after 4 days of storage $10{ }^{\circ} \mathrm{C}$ and $85 \%$ relative humidity. The coated tomatoes showed varied rates of change in concentration of gases over the period of storage. The tomatoes coated with the duration time of $3 \min \left(1.1 \% \mathrm{CO}_{2}\right.$ and $\left.19.3 \% \mathrm{O}_{2}\right)$ and $4 \mathrm{~min}(1.1 \%$ $\mathrm{CO}_{2}$ and $19.4 \% \mathrm{O}_{2}$ ) showed almost the equal change in concentrating of gases after 4 days of storage at $10{ }^{\circ} \mathrm{C}$ and $85 \%$ relative humidity (Fig. 3 (a) and (b).

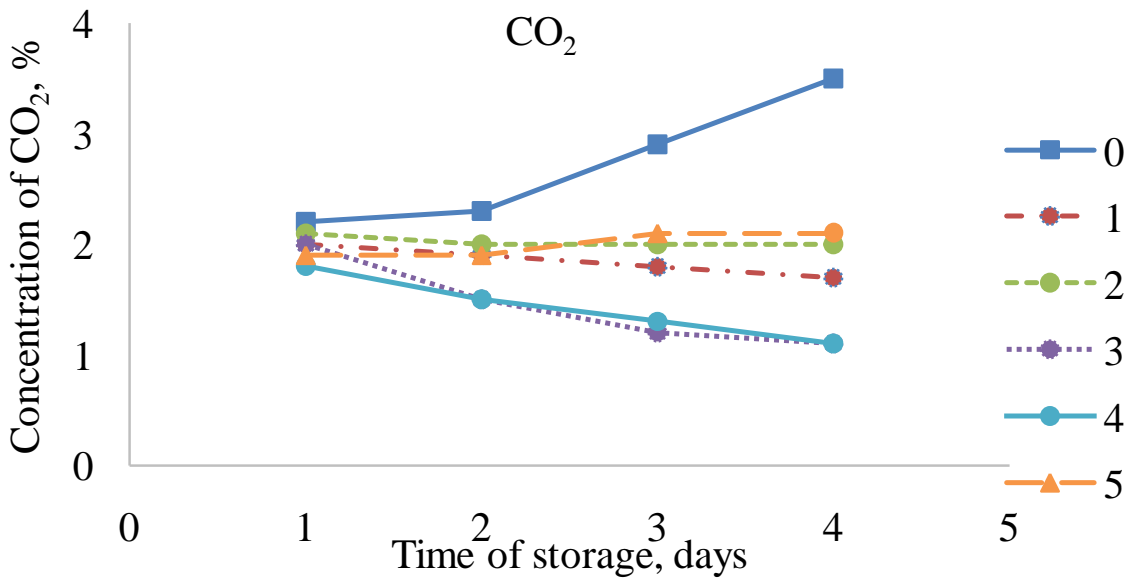

(a) 


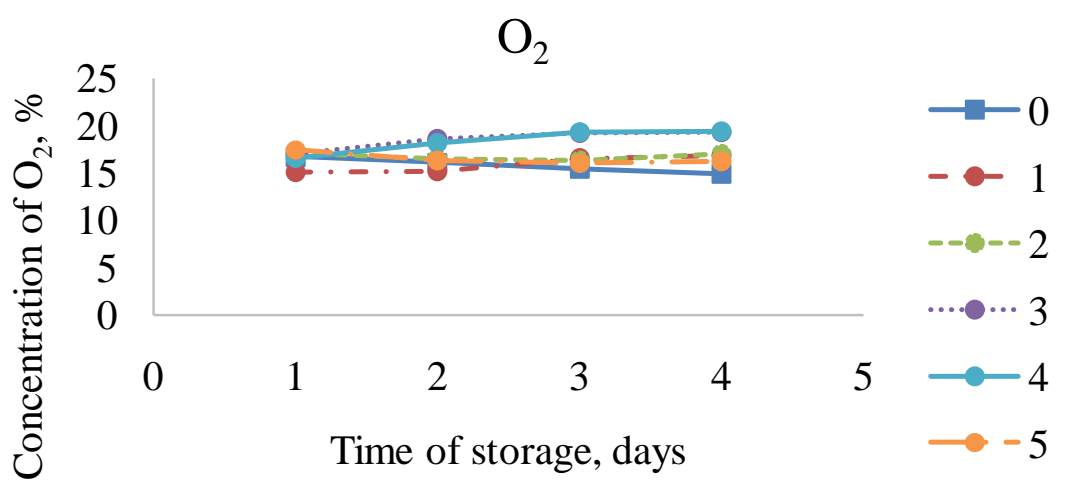

(b)

Figure 3:- Change in gas (a) $\mathrm{CO}_{2}$ and (b) $\mathrm{O}_{2}$ concentration of tomatoes stored in a closed system respirometer with the different duration of coating time.

\section{Coating Thickness:-}

The thickness of coating is an important parameter as it largely affects the functionality of coatings, typically the permeability in terms of $\mathrm{O}_{2}, \mathrm{CO}_{2}$ and water vapor transmission rate. Thickness of the coating did not vary significantly $(\mathrm{p}<0.5)$, however, an increase in coating thickness was noted with increase in dipping time of tomato peel. The coating was found to be $8.3 \pm 0.94,10.5 \pm 0.76,12.5 \pm 0.87,14 \pm 0.81$ micron for 2, 3, 4 and 5 min of coating duration, respectively. The thickness, however, of the coating could not be determined for 0.5 and 1 minduration of dipping time because of very slight differences. Coatings exceeding a critical thickness can cause detrimental effects of reduced internal $\mathrm{O}_{2}$ concentration and increasing $\mathrm{CO}_{2}$ concentration from anaerobic fermentation (Lin and Zhao, 2007). The thickness of coating varies with density, viscosity, surface tension, and draining time of the biopolymer solution (Cisneros-Zevallos and Krochta, 2003).

\section{Conclusion:-}

The tomatoes coated for $3 \mathrm{~min}$ and 4 min showed the minimum change in gas concentration i.e. $1.1 \% \mathrm{CO}_{2}$ and $19.3 \% \mathrm{O}_{2}$ for $3 \mathrm{~min}$ and $1.1 \% \mathrm{CO}_{2}$ and $19.4 \% \mathrm{O}_{2}$ for 4 min coating duration. However, the tomatoes coated for 4 min showed the least amount of physiological weight loss $(3.43 \%)$. The best conditions for the optimization of duration of dipping time can be found by balancing changes in gas concentration and weight loss, as both of these parameters are crucial and can greatly affect the shelf life of fresh produce. Therefore, the optimized duration can be selected as $4 \mathrm{~min}$, which uses $4.9 \pm 0.3 \mathrm{~g}$ of edible coating for one $\mathrm{kg}$ of tomatoes with the coating thickness of 12.5 \pm 0.87 micron.

\section{References:-}

1. Azarakhsh, N., Osman, A., Ghazali, H.M., Tan, C.P. and Mohd Adzahan, N. (2012): Optimization of alginate and gellan-based edible coating formulations for fresh-cut pineapples. Int. Food Res. J., 19(1): 279-285.

2. Babu, R., Singh, K., Jawandha, S.K., Alam, S.M., Jindal, S.K., Khuarana, D.S. and Narsaiah, K. (2014): Effect of pre-harvest spray of putrescine on shelf life and quality of tomato during storage. Int. J. Adv. Res., 2(10): 861-865.

3. Bhande SD, Ravindaran MR and Goswami TK. (2008): Respiration rates of banana fruits under aerobic conditions at different storage temperatures. J. Food Eng., 87: 116-123.

4. Bhattarai, D.R. and Gautam, D.M. (2006): Effect of Harvesting Method and Calcium on Post-Harvest Physiology of Tomato. Nepal Agric. Res. J., 7: 37-41.

5. Cisnero-Zevallos L, Krochta JM. (2003): Dependence of coating thickness on viscosity of coating solution applied to fruits and vegetables by dipping method. J Food Sci., 68: 503-10.

6. Gonzalez-Aguilar, G.A., Ayala-Zavala, J.F., Olivas, G.I., de la Rosa, L.A. and Alvarez-Parrilla, E. (2010): Preserving quality of fresh-cut products using safe technologies. J. Consum. Prot. Food Saf., 5: 65-72.

7. Lin, D. and Zhao, Y. (2007): Innovations in the development and application of edible coatings for fresh and minimally processed fruits and vegetables. Compr. Rev. Food Sci. Food Saf., 6: 60-75.

8. Mangaraj S and Goswami TK. (2011): Measurement and modelling of respiration rate of Guava (cv. Baruipur) for modified atmosphere packaging. Int. J. Food Prop., 14(3): 609-628. 
9. Mojevic MV and Tesanovic DB (2011): Influence of short anoxia treatment and maturity on quality and storage life of tomatoes. J. Agric. Sci., 56: 121-131.

10. Moneruzzaman, K.M., Hossain, A.B.M S., Sani, W., Saifuddin, M. and Alenazi, M. (2009): Effect of harvesting and storage conditions on the post-harvest quality of tomato (Lycopersicon esculentum Mill) cv. Roma VF. Aust. J. Crop Sci., 3(2):113-121.

11. Olivas, G.I. and Barbosa-Canovas, G.V. (2005): Edible coatings for fresh-cut fruits. Crit. Rev. Food Sci. Nutr., 45: 657-670.

12. Srividya, S., Reddy, P.S.S., Umajyothi, K., Sudhavani, V. and Reddy, A.R. (2014). Effect of different LDPE packaging material on shelf life and nutrition quality of tomato cv. Lakshmi under ambient conditions. Plant Archives, 14(2): 1123-1126.

13. Talasila PC, Chau KV and Brecht JK. (1992): Effects of gas concentrations and temperature on $\mathrm{O}_{2}$ consumption of strawberries. Trans. ASAE 35: 221-224.

14. Tapia, M.S., Rojas-Grau, M.A., Carmona, A., Rodriguez, F.J., Soliva-Fortuny, R. and Martin-Belloso, O. (2008): Use of alginate- and gellan-based coatings for improving barrier, texture and nutritional properties of fresh-cut papaya. Food Hydrocolloids, 22: 1493-1503.

15. Tosati JV, Oliveira DD, Lerin LA, Sarantopoulos CIGL and Monteiro AR (2015): Respiration rate of cherry tomatoes gas permeability of hydroxypropyl methyl cellulose based coating. International Journal of Emerging Technology and Advanced Engineering, 5: 281-287. 